\title{
MRI Thermometry Based on PARACEST Agents
}

\author{
Shanrong Zhang ${ }^{\star}, \dagger, \ddagger$, Craig R. Malloy ${ }^{\dagger}$, and A. Dean Sherry ${ }^{\star}, \dagger, \S$ \\ $\dagger$ Advanced Imaging Resonance Center, University of Texas Southwestern Medical Center, 5323 Harry Hines \\ Blvd, Dallas, TX 75390-8568
}

$\S$ Department of Chemistry, University of Texas at Dallas, P.O. Box 830688, Richardson, TX 75083-0688

Noninvasive temperature monitoring has many medical applications because of the close interrelationship between tissue temperature, metabolism and physiology. Such applications include the monitoring local hyperthermia for tumor ablation, ${ }^{1}$ the treatment of heart arrhythmias, ${ }^{2}$ the local drug delivery with thermosensitive microcarriers, ${ }^{3,4}$ and the controlled release of gene therapy using heat-sensitive promoters. ${ }^{5}$ Recently, magnetic resonance imaging (MRI) has been explored as a noninvasive technique for temperature mapping. ${ }^{6}$ The temperature dependence of several physical parameters of water have been used for MRI thermometry, including diffusion (D), ${ }^{7}$ spin lattice relaxation $\left(\mathrm{T}_{1}\right)^{8}$ and shifts in the water proton resonance frequency (PRF). ${ }^{9}$ Among these methods, PRF thermometry is most widely applied because it less dependent on tissue composition than the other parameters. This method is based on an early discovery of Hindman, 10 who found that the water proton resonance frequency decreases linearly by $c a .0 .01 \mathrm{ppm} /{ }^{\circ} \mathrm{C}$ over the range, $37-43^{\circ} \mathrm{C}$. However, motion effects and magnetic field inhomogeneities can limit the error of this method to $\pm 1-3^{\circ} \mathrm{C}$. ${ }^{1}$ This level of accuracy is not be problematic if the temperature differences are large (i.e., during tumor ablation) but is impractical if temperature differences are small. For example, the temperature heterogeneity in carotid atherosclerotic plaques is reportedly $0.2-0.3^{\circ} \mathrm{C} .{ }^{11}$ Alternatively, exogenous probes based on either paramagnetic relaxation agents that alter $\mathrm{T}_{1}$ or $\mathrm{T}_{2}{ }^{12,13}$ or hyperfine shift reagents that alter the chemical shift of some observable nucleus 14,15 are much more sensitive to temperature but suffer other experimental limitations for in vivo use largely related to the concentrations required and poor spatial resolution. Thus, a method that might allow accurate measures of small temperature differentials would be highly desirable. Here we report a novel MRI thermometric method based on the use of exogenous PARACEST $^{16}$ (paramagnetic chemical exchange saturation transfer) agents that sense and report temperature via the bulk water signal rather than a nucleus on the agent itself.

A new MRI contrast method was recently introduced where the bulk water signal intensity is altered via chemical exchange saturation transfer (CEST). ${ }^{17}$ This was later extended to paramagnetic systems and such small molecule agents are now referred to as PARACEST agents. ${ }^{16}$ By selective pre-saturation of highly shifted spin pool, A (i.e. $\mathrm{Ln}^{3+}-\mathrm{H}_{2} \mathrm{O}$ or $\mathrm{Ln}^{3+}-$ amide protons), the MRI signal intensity of any exchanging partner spin partner, B (i.e., bulk water) will decrease in intensity if the kinetics are appropriate. For a simple 2-site exchange system, ${ }^{16}$ this may be described by $M_{S B} / M_{O B} \approx\left(1+k_{B A} T_{1 B}\right)^{-1}$, where $M_{S B}$ and $M_{O B}$ are ${ }^{1} \mathrm{H}$ signal intensities of B (bulk water) with and without pre-saturation of spin A, $T_{1 B}$ is the spin lattice relaxation time of $\mathrm{B}$ and $k_{B A}$ is the exchange rate constant of water from $\mathrm{B}$ to A. Since $k_{B A}$ is directly related to temperature via the classical Arrhenius equation, changes in $M_{S B} /$ $M_{O B}$ may be used to measure temperature if the agent concentration is known. ${ }^{18}$ This requirement is difficult for in vivo applications because here the agent concentration is usually

E-mail: zhangs@u.washington.edu; sherry@utdallas.edu.

*Current address: Department of Radiology, University of Washington, Box 357115, 1959 NE Pacific St, Seattle, WA 98195-7115 
unknown. However, a second temperature dependent feature of such systems is the hyperfine position $(\delta$, in $\mathrm{ppm})$ of the exchanging site on the PARACEST agent; for example, hyperfine shift of lanthanide bound water protons $\left(\mathrm{Ln}^{3+}-\mathrm{H}_{2} \mathrm{O}\right)$ can vary from $+500 \mathrm{ppm}$ for typical $\mathrm{Tm}^{3+}$ complexes to $-800 \mathrm{ppm}$ for Dy ${ }^{3+}$ complexes. ${ }^{19}$ Such hyperfine shifts are highly temperature dependent ${ }^{20}$ and this feature has been the basis of previous shift reagent-based thermometry experiments. ${ }^{14,15}$ PARACEST thermometry, however, differs in that the MRI readout signal is from bulk water present at $c a .55 \mathrm{M}$ thereby offering the potential of thermometry measurements with high spatial resolution. Variable-temperature data (Figure S1) indicates that ${ }^{1} \mathrm{H}$ chemical shift of the $\mathrm{Ln}^{3+}$-bound water resonance vary linearly over 20$50^{\circ} \mathrm{C}$ according to $\delta_{\mathrm{PPM}}=6.9^{*} \mathrm{~T}-944.7$ for $\mathrm{Dy}(\mathbf{1})^{3+}$ and $\delta_{\mathrm{PPM}}=-0.4 * \mathrm{~T}+64.6$ for $\mathrm{Eu}(2)^{-}$ (Scheme 1). These temperature responses are $\sim 690$ and $\sim 40$-fold greater than the PRF response $\left(-0.01 \mathrm{ppm} /{ }^{\circ} \mathrm{C}\right)$.

The key to PARACEST thermometry then is to locate the ${ }^{1} \mathrm{H}$ chemical shift $(\delta)$ of the $\mathrm{Ln}^{3+}$ bound water molecule in images with high spatial resolution. This may be accomplished by measuring the residual bulk water $\mathrm{Z}$ magnetization after a series of selective pre-saturation pulse that is varied over a small range of frequencies spanning the Larmor frequency of the $\mathrm{Ln}^{3+}$-bound water molecule. ${ }^{21}$ For temperature imaging, this may be expanded to 3dimensional space by acquiring one image at each saturation offset (Scheme 2). By tracing the intensity changes of a specific imaging pixel along the imaging series (Figure S2), a plot of pixel intensity versus frequency offset yields a typical Z-spectrum. The temperature of this pixel is obtained by identifying the minimum intensity point which corresponds to the chemical shift of the $\mathrm{Ln}^{3+}$-bound water. Substitution into one of the linear relationships reported above yields the temperature in that pixel. A similar procedure is then repeated for all pixels in the image or region of interest to generate a temperature map.

To test the feasibility of this method, a $1 \mathrm{~cm} \mathrm{OD}$ vial containing $10 \mathrm{mM} \mathrm{Eu}(2)^{-}$in water (pH 7) was imaged at different controlled temperatures using a $2 \mathrm{~cm} \mathrm{RF}$ surface coil and a $4.7 \mathrm{~T}$ animal imaging magnet. Typically, a series of CEST images were obtained by applying a $2 \mathrm{~s}$ presaturation pulse $\left(\mathrm{B}_{1}=735 \mathrm{~Hz}\right)$ over a small range of frequencies surrounding the $\mathrm{Eu}^{3+}$-bound water position (50 ppm). In each case, a minimum was observed in $M_{S B} / M_{O B}$ over this frequency range and the frequency of this minimum provided a direct readout of temperature using the appropriate linear equation. The temperature images illustrated in Figure 1 show that even small temperature gradients across this $1 \mathrm{~cm}$ vial are easily detected by MRI. The temperature images as indicated by the color bars matched closely to those of the regulated air flowing over the sample. An in-plane temperature spatial resolution of $0.15 \times 0.15 \mathrm{~mm}^{2}$ was obtained using this phantom. The temporal resolution ( $\sim 3 \mathrm{~min})$ of the experiment could be improved substantially by varying the saturation frequency over a narrower frequency range that spans the expected bound water resonance frequency and by using shorter presaturation periods. ${ }^{16}$

Although this method offers considerable potential for in vivo temperature mapping, factors such as RF power deposition (SAR limits), inherent tissue magnetization transfer (MT) effects, the tissue biodistribution and toxicity of such complexes and the exchange properties of a PARACEST agent in tissue must be assessed. It is important to point out that values of $k_{B A}$ and $T_{1 B}$ need not to be known a priori for temperature mapping; the only requirement is that these physical parameters be appropriate for CEST. $T_{1 B}$ is of course a feature of tissue water and cannot be easily changed while $k_{B A}$ is controlled by both the lanthanide ion and the ligand structure. ${ }^{19}$ Clearly, optimal PARACEST agents for temperature mapping can be identified by adjusting these chemical variables. Imaging studies have been performed in animals after infusion of negatively charged LnDOTA-tetraamide complexes similar to $\mathrm{Eu}(\mathbf{2})^{-}$without adverse side-effects ${ }^{22}$ so we anticipate that $\mathrm{Eu}(\mathbf{2})^{-}$will be well tolerated in vivo at the concentrations required for PARACEST thermometry. The RF power requirements depend 
upon many factors including coil design, volume of power deposition, and features of the PARACEST agent itself ${ }^{16}$ but others have shown that in vivo CEST imaging can be performed within acceptable SAR limits. ${ }^{23}$ Finally, the inherent tissue MT effect could potentially interfere with PARACEST temperature mapping depending on the magnitude of the MT effect in the tissue under investigation. If needed, corrections for MT could be performed by measuring asymmetry differences between presaturation frequencies on each side of the bulk water resonance. ${ }^{23}$

In summary, the feasibility of PARACEST-based MRI thermometry has been demonstrated in vitro. In comparison with the classical PRF thermometry, the temperature responses of this method is substantially improved by factors of $\sim 690$ and $\sim 40$-fold for two prototype systems, $\operatorname{Dy}(\mathbf{1})^{3+}$ and $\operatorname{Eu}(\mathbf{2})^{-}$. This method is especially attractive because the imaging readout signal is bulk water $(55 \mathrm{M})$ which offer the potential of much higher MRI spatial resolution than current spectral imaging methods.

\section{Supplementary Material}

Refer to Web version on PubMed Central for supplementary material.

\section{Acknowledgements}

This work was supported in part by grants from the Robert A. Welch Foundation (AT-584) and the National Institutes of Health (CA-115531 and RR-02584).

\section{References}

1. Weidensteiner C, Quesson B, Caire-Gana B, Kerioui N, Rullier A, Trillaud H, Moonen Chrit TW. Magn Reson Med 2003;50(2):322. [PubMed: 12876709]

2. Levy S. Arch Mal Coeur Vaiss 1995;88:1465. [PubMed: 8745619]

3. Weinstein JN, Magin RL, Yatvin MB, Zaharko DS. Science 1979;204:188. [PubMed: 432641]

4. Kim S. DRUGS IN R\&D 1993;46:618.

5. Madio D, van Gelderen P, Olson A, de Zwart J, Fawcett T, Holbrook N, Mandel M, Moonen C. J Magn Reson Imaging 1998;8(1):101. [PubMed: 9500267]

6. Quesson B, Zwart JAd, Moonen CTW. J Magn Reson Imaging 2000;12:525. [PubMed: 11042633]

7. Le Bihan D, Delannoy J, Levin RL. Radiology 1989;171(3):853. [PubMed: 2717764]

8. Parker DL, Smith V, Sheldon P, Crooks LE, Fussell L. Med Phys 1983;10:321. [PubMed: 6877179]

9. Ishihara, Y.; Calderon, A.; Watanabe, H.; Mori, K.; Okamoto, K.; Suzuki, Y.; Sato, K.; Kuroda, K.; Nakagawa, N.; Tsutsumi, S. Eleventh Annual Meeting of the Society of Magnetic Resonance in Medicine; Berkeley, CA. 1992. p. 4803

10. Hindman JC. J Chem Phys 1966;44:4583.

11. Casscells W, Hathorn B, David M, Krabach T, Vaughn WK, McAllister HA, Bearman G, Willerson JT. Lancet 1996;347(9013):1447. [PubMed: 8676628]

12. Fossheim, SL.; ll'yasov, KA.; Wiggen, UN.; Rogstad, A.; Hennig, J.; Klaveness, J.; Bjornerud, A. ISMRM. Philadelphia: 1999. p. 725

13. Muller RN, Vander Elst L, Laurent S. J Am Chem Soc 2003;125(27):8405. [PubMed: 12837114]

14. Zuo CS, Bowers JL, Sherry AD, Clouse ME. Radiology 1995;197:423.

15. Hekmatyar SK, Hopewell P, Pakin SK, Babsky A, Bansal N. Magn Reson Med 2005;53(2):294. [PubMed: 15678553]

16. Zhang S, Merritt M, Woessner DE, Lenkinski RE, Sherry AD. Acc Chem Res 2003;36(10):783. [PubMed: 14567712]

17. Ward KM, Aletras AH, Balaban RS. J Magn Reson Imaging 2000;143(1):79.

18. Terreno E, Castelli DD, Cravotto G, Milone L, Aime S. Invest Radiol 2004;39(4):235. [PubMed: 15021328] 
19. Zhang S, Sherry AD. J Solid State Chem 2003;171(12):38.

20. Peters JA, Huskens J, Raber DJ. Prog Nucl Magn Reson Spectrosc 1996;28:283.

21. Grad J, Bryant RG. J Magn Reson Imaging 1990;90(1):1.

22. Raghunand N, Howison C, Sherry AD, Zhang SR, Gillies RJ. Magn Reson Med 2003;49(2):249. [PubMed: 12541244]

23. Zhou JY, Lal B, Wilson DA, Laterra J, van Zij1 PCM. Magn Reson Med 2003;50(6):1120. [PubMed: 14648559] 


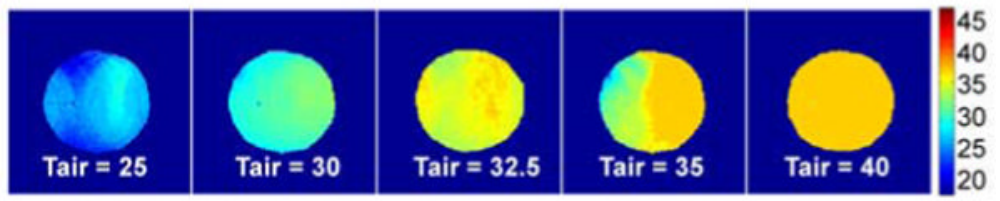

Figure 1.

Temperature maps of a phantom containing $1 \mathrm{~mL}$ of $10 \mathrm{mM} \mathrm{Eu(2)}$ - in water at $\mathrm{pH}$ 7.0. The temperatures of the air flowing over the sample are indicated in each figure while those reported by imaging are shown by the color bar (in units of ${ }^{\circ} \mathrm{C}$ ). 


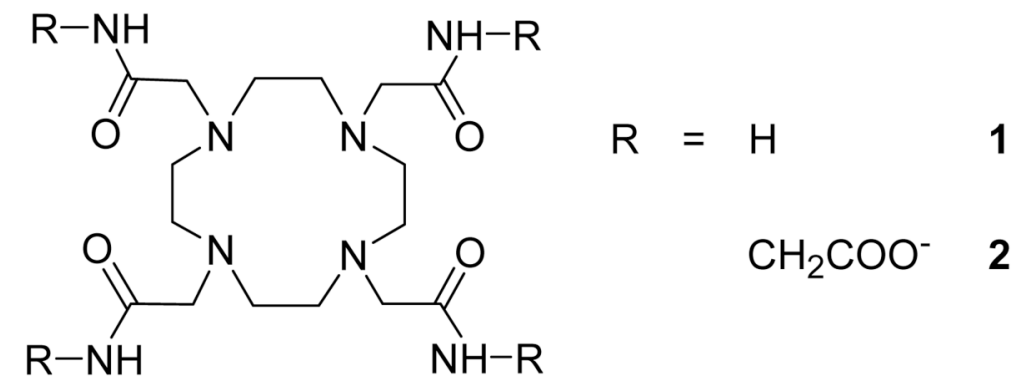

Scheme 1.

Molecular structures of ligands $\mathbf{1}$ and $\mathbf{2}$. 


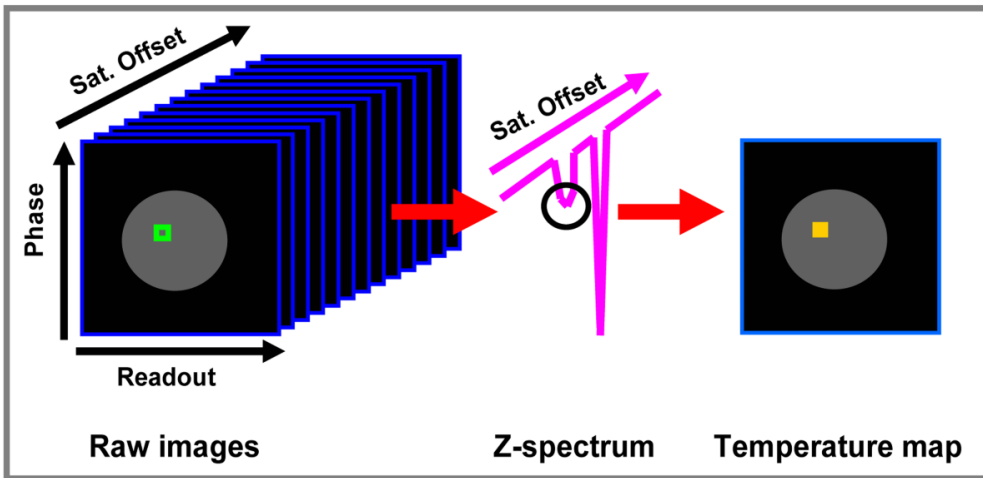

Scheme 2.

A scheme illustrating the basic procedure for generating a temperature map based on PARACEST MRI thermometry. 